\title{
Penerapan Belajar Mandiri Dengan Strategi Efektif Pada Masa Pandemi Covid 19 Bagi Remaja Hkbp Duren Jaya Bekasi
}

\author{
Hotmaulina Sihotang ${ }^{1^{*}}$, Bernadetha Nadeak ${ }^{2)}$, dan Rospita Siregar ${ }^{3)}$ \\ 1,2,3 Universitas Kristen Indonesia, Indonesia \\ E-mail: hotmaulina.sihotang@uki.ac.id; bernadetha.nadeak@uki.ac.id; \\ rospita.siregar@uki.ac.id
}

\begin{abstract}
Abstrak
Pengabdian kepada masyarakat (PkM) bertujuan untuk memberikan pengetahuan kepada remaja peserta sidi dan orangtua jemaat HKBP Duren Jaya Bekasi dan mengaplikasikannya. Orangtua yang mengawasi anak di rumah di masa pandemi Covid 19. Metode pelaksanaan dengan survey dan pelaksanaan PkM secara offline mengikuti aturan pembatasan sosial berskala besar (PSBB) dan protokol kesehatan, yakni kapasitas gereja 360 orang. Peserta dan fasilitator 65 orang. Setiap masuh ruangan cek suhu bisa masuk jika suhu $<37.5^{\circ} \mathrm{C}$ dan pakai masker. Hasil PkM ada yang diperoleh yakni (1) terlaksananya penandatanganan MoU dan MoA, (2) Remaja mengetahui strategi efektif belajar mandiri di rumah karena masih online learning, (3) Orangtua mengerti tugasnya memonitoring anak dan memberikan reward misalnya mengijinkan anak order makanan sesuai dengan kesenangan agar merasa senang belajar di rumah, (4) menyeimbangkan kecerdasan spiritual, kecerdasan emosional dan pengetahuan agar menjadi generasi penerus berkarakter kristiani yang tangguh.
\end{abstract}

Kata kunci: Penerapan belajar mandiri; efektif; pandemi covid 19

\begin{abstract}
Community service (PkM) aims to provide knowledge to youth participants and parents in HKBP Duren Jaya Bekasi. Especially due to the pandemic of COVID 19, parents' role is needed to supervise their children while online learning. The methods are used survey and offline seminar by following the rules of large-scale social restrictions (PSBB) and health protocol, which is only attended by participants and facilitators who fill a quarter of the church's capacity for around 360 people. There is also some security checking first, such as all the participants are compulsory to wear a mask, sanitize their hands, and do temperature checks. They are allowed to enter if the temperature is detected $<37.5^{\circ} \mathrm{C}$. The results of the PkM were obtained (1) the signing of the MoU and the MoA, (2) Adolescents knew the effective strategies of independent learning at home due to the online learning, (3) Parents understood their task of monitoring their children and giving them any rewards, for example allowing their children to order what food they want to so they still feel happy while online learning, (4) Balancing spiritual, emotional and knowledge to form a formidable generation.
\end{abstract}

Keywords: Aplication of independent learning; effective; the pandemic of Covid 19 


\section{PENDAHULUAN}

Pandemi

Coronavirus

Disease (Covid-19) mengubah segalanya. Salah satu yang mengalami dampak serius adalah institusi pendidikan. Berbagai agenda pendidikan nasional mengalami perubahan. Proses pembelajaran di lakukan secara jarak jauh, ujian nasional ditiadakan, dan murid yang magang dan belajar lapangan juga ditarik. Kondisi demikian mengejutkan sekaligus menimbulkan kegagapan. Di tengah pandemi Covid-19 saat ini, ada banyak sekali tantangan yang harus dihadapi oleh guru, orangtua, dan murid. Guru menghadapi era baru dan situasi yang tidak mudah. Secara radikal guru harus mengubah pola pembelajaran. Penggunaan teknologi menjadi satusatunya cara untuk melaksanakan pembelajaran jarak jauh (PJJ). Guru yang belum terbiasa dengan perkembangan teknologi mengalami banyak kendala. Belum lagi guru harus melakukan penilaian kepada murid.

Orangtua juga mengalami tantangan yang tidak ringan. Ada kondisi baru di mana sebelumnya setiap anggota keluarga beraktivitas di luar rumah, saat ini semuanya beraktivitas di rumah. Orangtua bekerja dari rumah dan anak belajar di rumah. Faktanya, kondisi yang terjadi tidak sesederhana itu. Ketika semua aktivitas di lakukan di rumah ternyata banyak permasalahan juga yang harus dibawa ke rumah. Tidak sedikit orangtua yang bekerja lebih keras karena kondisi ekonominya menurun, orangtua mengalami pemutusan hubungan kerja, dan ada anggota keluarga yang sakit. Di sisi lain orangtua yang sebelumnya memercayakan pendidikan anak kepada guru dan sekolah harus turut ambil peran. Orangtua akhirnya juga merasa kesulitan karena harus berperan sebagai guru, pengajar, dan pemimpin di rumah. Kondisi demikian tentu sangat memengaruhi segala aspek kehidupan dalam keluarga.

Demikian juga yang dialami oleh murid. Mereka merasa sulit karena tidak terbiasa belajar secara mandiri. PJJ yang sudah berjalan belum menemukan kondisi ideal bagi murid. Tentu karena hal ini dipengaruhi oleh beragam faktor. Bahkan dari persepsi murid, model PJJ yang dilakukan selama masa pandemi tidak membuat mereka nyaman dan bahagia.

Hasil survei yang dilakukan oleh Komisi Perlindungan Anak Indonesia (KPAI) menunjukkan tingkat persepsi murid terhadap PJJ. Survei tersebut dilakukan pada 13-20 April 2020 terhadap 1.700 murid di berbagai jenjang. Hasilnya adalah sekitar 76,7 persen mengaku tidak senang mengikuti PJJ. Terdapat 81,8 persen murid yang menyatakan selama empat pekan PJJ hanya diberi tugas oleh guru tanpa adanya diskusi ataupun penjelasan materi. Selain itu sebanyak 73,2 persen murid merasa mendapat tugas berat dari guru (Kompas, 28/04/2020). 
Beragam permasalahan pada masa pandemi tersebut tentu sangat berpengaruh pada pola pengasuhan dan pendidikan anak-anak. Dibutuhkan strategi yang tepat agar proses PJJ dapat berjalan dengan efektif dan menyenangkan. Untuk mencapainya ada beberapa strategi yang dapat diterapkan. Kemampuan belajar mandiri yang dimiliki oleh pebelajar didefinisikan sebagai kemampuan untuk berinisiatif dalam mengatur (regulate), mengelola dan mengontrol proses belajarnya untuk mengatasi berbagai masalah dalam belajar dengan mempergunakan berbagai alternatif atau strategi belajarself-regulation memfokuskan pada bagaimana pebelajar menggerakkan, mengubah, dan mempertahankan kegiatan belajar baik secara sendiri maupun pada lingkungan sosialnya, dalam konteks instruksional informal maupun formal (Darmayanti, T., 2008). Hal ini dengan menerapkan anak belajar seperti halnya pada saat belajar di sekolah. Dalam arti, anak tetap dibiasakan memiliki disiplin belajar dengan menyediakan ruang dan waktu belajar secara khusus. Jika memungkinkan orangtua dapat menyediakan sudut belajar di rumah dengan beragam alat belajar yang dimiliki. Agar proses belajar di rumah berjalan efektif dibutuhkan kolaborasi. Belajar pada kondisi saat ini memang tidak mudah. Namun, jika semua memiliki kesadaran bersama maka akan dapat berjalan lebih mudah. Kondisi yang demikian semakin membuka kesadaran bahwa pendidikan ternyata tidak hanya dapat dilakukan di sekolah.

Strategi yang diterapkan sekolah tentunya beragam dan bukan berarti tanpa kendala, bagi sekolah yang sudah terbiasa melaksanakan pembelajaran berbasis digital atau daring sudah tentu bukan menjadi masalah, apalagi bagi guru sudah mahir melakukan penilaian portofolio dengan berbagai tugas yang bervariasi sehingga tidak menjadi beban bagi siswanya yang saat ini juga dikeluhkan oleh para orangtua, bahwa saat mendampingi siswa belajar di rumah merupakan beban tersendiri bagi orangtua yang tidak memiliki latar belakang pendidikan yang cukup ataupun sarana dan fasilitas yang memadai. Kendala kendala salah satu diantaranya siswa tidak memiliki buku paket sebagai sumber belajar di rumah karena selama ini buku hanya dipinjamkan oleh sekolah dan hanya digunakan saat pembelajaran di kelas, buku tersebut tidak bisa dibawa pulang oleh siswa karena jumlahnya terbatas sehingga penggunaannya harus bergantian dengan siswa lain. Guru yang ingin membuatkan Lembar kerja untuk siswa juga terkendala distribusi tugas tersebut ke masing masing siswa mengingat jika tugas tersebut diambil di sekolah dikhawatirkan akan membuat kerumunan. Siswa tidak bisa mengakses sumber belajar online karena tidak memiliki perangkat digital (HP android, komputer, dsb) , tidak adanya 
koneksi atau jaringan internet pada wilayah tersebut, dan tidak adanya listrik.

Belajar secara daring tentunya memiliki tantangan tersendiri. Karena dianggap lebih bebas dan fleksibel, peserta didik justru dituntut agar memiliki komitmen untuk melakukan pembelajaran secara mandiri di rumah. Pembelajaran secara daring memiliki tantangan dalam pengawasan agar peserta didik terus melakukan kegiatan belajar mengajar sesuai dengan waktu belajar tatap muka. Selain itu, tentunya perangkat teknologi seperti smartphone atau laptop serta jaringan internet yang baik harus-tersedia.

$$
\text { Belajar mandiri merupakan }
$$
kegiatan belajar aktif yang didorong oleh niat atau motif untuk menguasai suatu kompetensi gun a untuk menyelesaikan suatu masalah, hal tersebut

dibangun dengan bekal pengetahuan at au kompetensi yang telah dimiliki. Belajar mandiri tidak berarti belajar sendiri. Belajar mandiri bukan merupakan usaha untuk mengasingkan siswa/peserta didik dari teman belajarnya dan dari guru/instrukturnya. Hal yang terpenting dalam proses belajar mandiri adalah peningkatan kemampuan dan keterampilan siswa/peserta didik dalam proses belajar tanpa bantuan orang lain, sehingga pada akhirnya siswa/peserta didik tidak tergantung pada guru/instruktur, pembimbing, teman atau orang lain dalam belajar.
Dalam belajar mandiri peserta didik akan berusaha sendiri dahulu untuk memahami isi pelajaran yang dibaca atau dilihatnya melalui media pandang dengar. Kalau mendapat kesulitan, barulah peserta didik akan bertanya atau mendiskusikannya dengan teman, guru/instruktur, atau orang lain. Peserta didik yang mandiri akan mampu mencari sumber belajar yang dibutuhkannya. Hasil penelitian Sihotang H. (2010) menyatakan ada hubungan gaya belajar dan kemampuan berpikir kritis dengan hasil belajar. Pada masa pandemi covid 19 mengharuskan PJJ. Tentu para pebelajar hendaklah menyesuaikan agar hasil belajar dapat tetap berprestasi. Sedangkan hasil penelitian Suardana, I. K. (2012) model self directed learning (SDL) adalah model pembelajaran yang memberikan otonomi bagi mahasiswa dalam mengelola belajarnya dengan langkah-langkah pembelajaran meliputi perencanaan, monitoring, dan evaluasi. Pebelajar harus memiliki perencnaan sesuai jadwal, monitoring dilakukan oleh orangtua dan evaluasi dilakukan oleh guru.

$$
\text { Belajar merupakan proses }
$$
perkembangan. Artinya hasil belajar berupa perubahan perilaku secara berangsur-angsur (tidak terjadi sekaligus). Oleh karena itu, materi pelajaran harus diajarkan secara bertahap dan berkesinambungan. Siswa akan belajar lebih giat bila ia merasa berhasil, keberhasilan akan menjadi pendorong belajar. Dengan demikian, selain materi 
pelajaran disesuaikan dengan kemampuan dan pengalaman siswa, pelajaran juga harus disajikan dengan menyenangkan. Belajar terjadi secara individual, hal ini dikarenakan seorang siswa memiliki perbedaan dari siswa lain dalam belajar.

Komponen-komponen sistem belajar mandiri meliputi falsafah dan teori, kebutuhan, organisasi peserta, program, produksi, penyebaran, pemanfaatan, organisasi, tenaga, sarana, prasarana, bantuan dan pengawasan, kegiatan belajar dan penilaian. Semua komponen ini saling berkaitan dan terintegrasi dalam suatu kesatuan. Secara operasional, pengertian ssistem belajar mandiri merupakan suatu pola konseptual dan tindakan.

Terdapat dua hal esensial sehububungan dengan hal ini. Pertama, pembelajaran mandiri mengharuskan siswa memiliki beberapa keterampilan dan pengetahuan tertentu seperti mengambil tindakan, keterampilan bertanya, membuat keputusan, berpikir kreatif dan kritis, memiliki kesadaran diri dan mampu bekerja-sama. Kedua, adalah mengharuskan siswa benar-benar melakukan hal tersebut. Pelatihan keterampilan belajar mandiri (PKBM) berpengaruh terhadap motivasi belajar mahasiswa pada sistem belajar jarak jauh di UPBJJ-UT Ternate (Anfas, A. : 2020). Intinya adalah dimana anak tidak hanya belajar secara 'teoritis' dengan membaca, melihat dan menonton saja, melainkan juga siswa aktif bertindak, learning by doing dimana siswa mencari dan menggabungkan informasi secara aktif dari masyarakat, ruang kelas maupun suber lainya, lalu menggunakannya untuk alasan tertentu sehingga informasi tersebut akan tersimpan dalam ingatan.

Berdasarkan uraian tersebut maka perlu dibantu anak remaja menuntun belajar mandiri dengan strategi efektif.

\section{METODE}

Studi awal dengan survey ke HKBP Duren Jaya dengan melakukan wawancara Pdt Rittar Simorangkir, S.Th, Sintua D.H. Tambunan dan perwakilan orang tua remaja pelajar sidi. Studi awal bertujuan untuk melakukan analisis kebutuhan dan mengetahui kondisi awal para remaja belajar sidi dan remaja bukan belajar sidi. Semula kegiatan dilakukan pada 2 Mei 2020 namun karena pandemi Covid 19 maka ditunda sehingga materi diubah untk menyesuaikan kebutuhan.

Berhubung adanya perubahan materi tim menindaklanjuti kembali dengan pihak gereja dan orangtua pelajar sidi dan melakukan rapat pada Sabtu, 4 Juli 2020 bertempat di kantor konsistori gereja dihadiri oleh Pdt. Panatas Manalu, S.Th, Pdt Rittar Simorangkir, S.Th, dan perwakilan orangtua pelajar sidi.

Pengabdian kepada masyarakat (PkM) dilaksanakan pada tanggal 18 Juli 2020 secara offline di gereja HKBP Duren Jaya Bekasi Timur dengan mengikuti aturan PSBB dan protokol kesehatan. Kapasitas gereja 260 orang dan sebelum masuk ke gereja cek suhu tubuh dimana 
suhu tubuh yang diijinkan masuk dibawah $37.5^{\circ} \mathrm{C}$, cuci tangan, pakai masker dan diatur oleh petugas kesehatan dari gereja. Kegiatan dibatas karena kondisi pandemi Covid 19.

a. Peserta PkM adalah pelajar sidi berusia 16-17 tahun (pelajar SMA kelas XI dan XII), orangtua pelajar sidi (dibatasi 1 orang), perwakilan majelis gereja.

b. Alat dan bahan

Alat yang dipakai dalam kegiatan PkM adalah Mic 5 buah, Proyektor, Laptop. Bahan yang digunakan materi dari para narasumber, latihan membaca cepat dan kuisioner yang diisi oleh pelajar sidi dengan google form.

c. Metode
Metode PkM dengan seminar, dan tanya jawab. Sebelum seminar terlebih dahulu penandatangan MoU dan MoA pihak PPs UKI dengan pihak gereja HKBP Duren Jaya. Pihak UKI oleh Direktur Program Pascasarjana, Dr. Bintang Simbolon, M.Si dan dari pihak gereja HKBP Duren Jaya oleh pendeta resort HKBP Duren Jaya, Pdt. Pantas Manalu, S.Th disaksikan oleh Pdt. Rittar Simorangkir, S.Th, narasumber, majelis gereja, orangtua dan pelajar sidi. PkM diliput oleh media massa. Narasumber dari UKI dan juga dari BNN yakni Prof. Benny Tunggul, HS, Ph.D untuk melengkapi materi untuk membekali para pelajar sidi yang didampingi oleh orangtua.

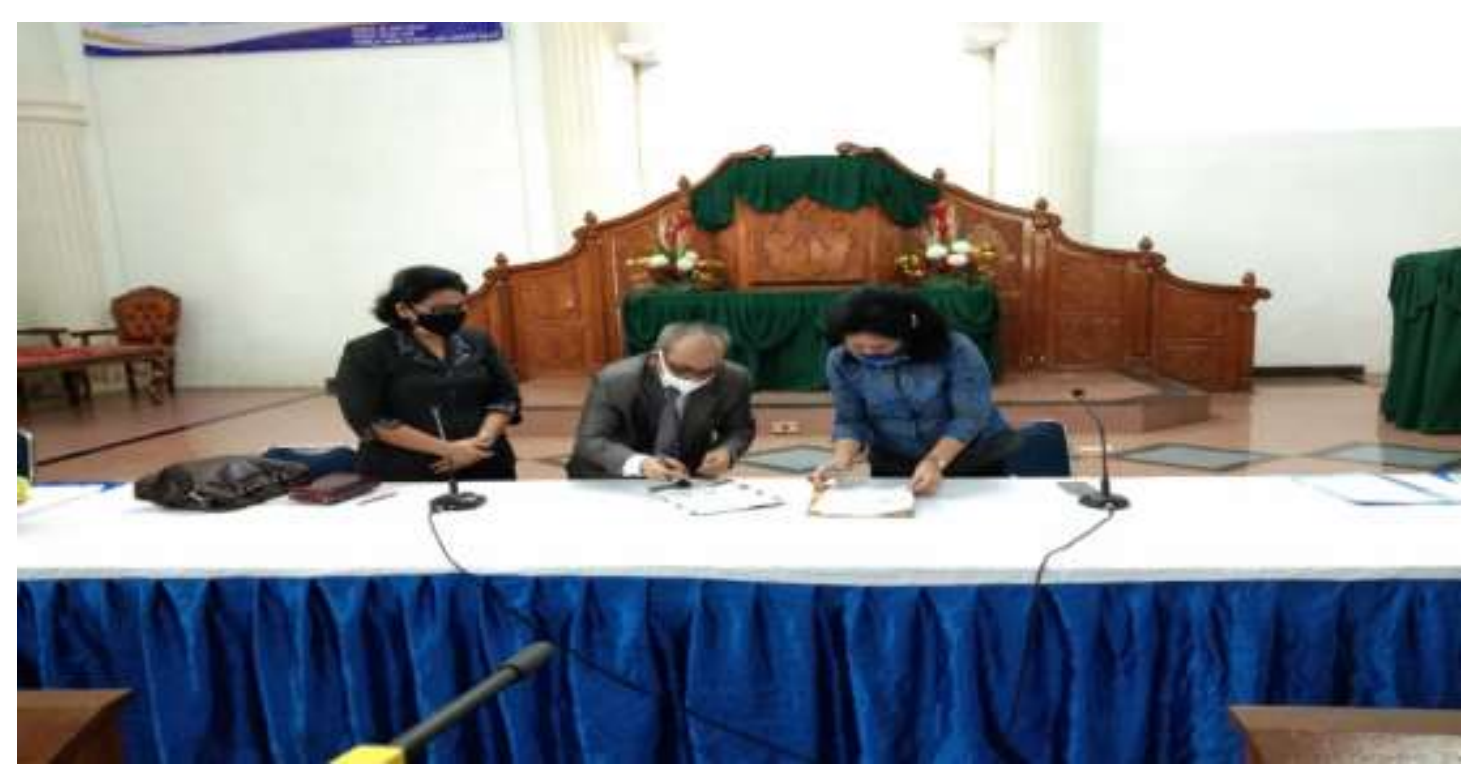

Penandatangan MoU dan MoA antara UKI dengan Gereja HKBP Duren Jaya Bekasi Direktur PPs UKI, Dr. Bintang Simbolon, M.Si dengan Pendeta Resort HKBP Duren Jaya, Pdt. Pantas Manalu, S.Th 


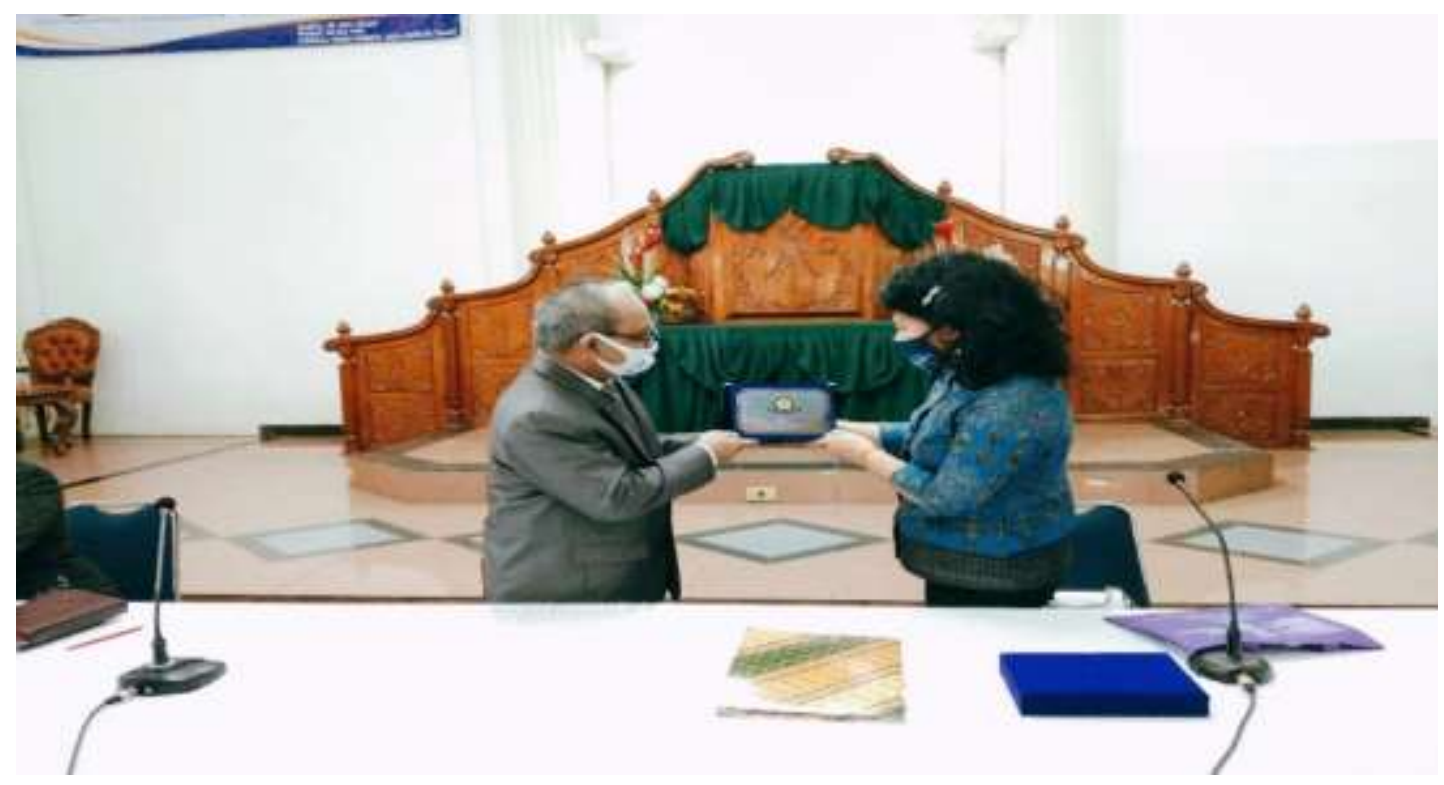

Penyerahan Plakat UKI ke Pendeta Resort HKBP Duren Jaya

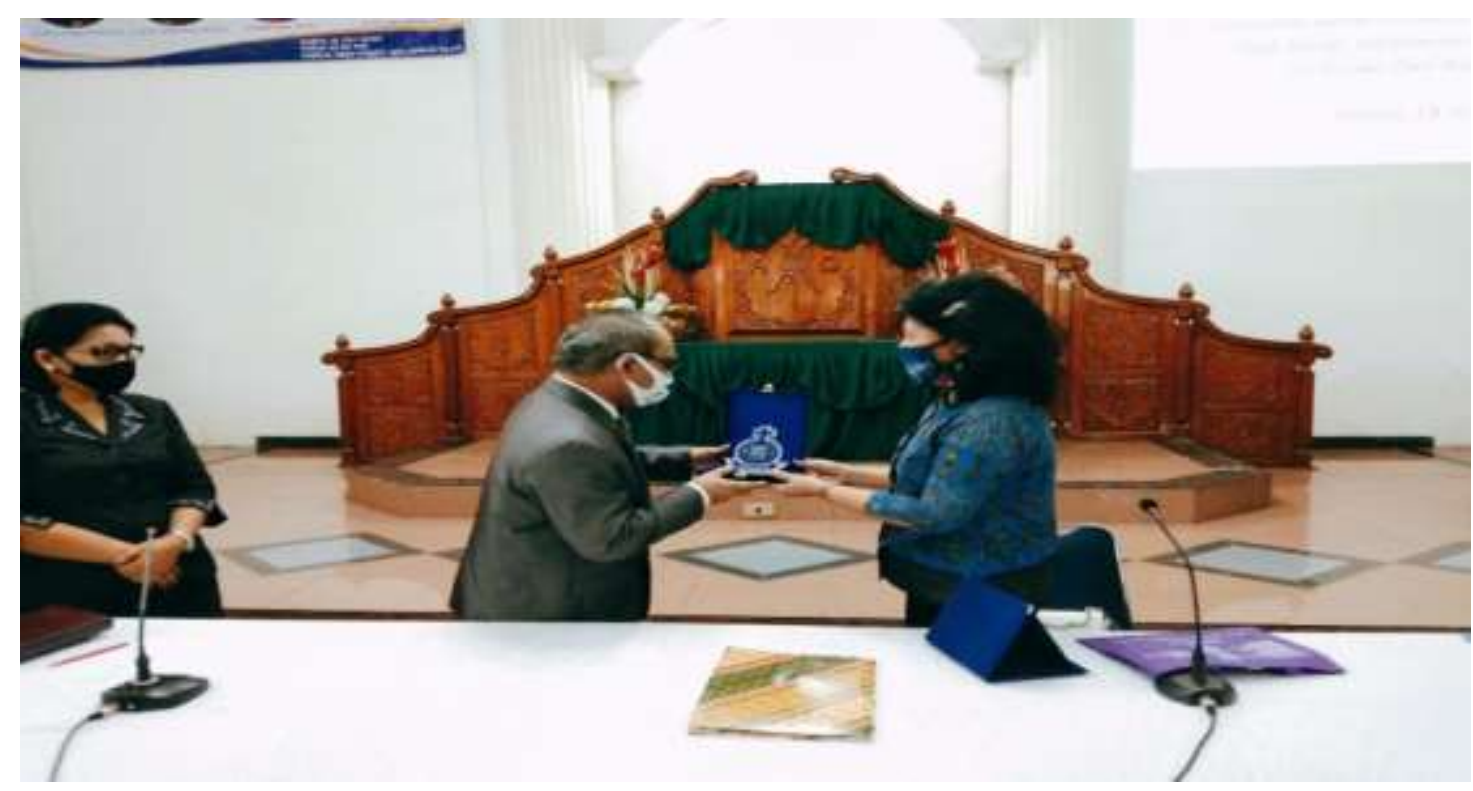

Penyerahan Plakat Gereja HKBP Duren Jaya ke Direktur PPs UKI 


\section{d. Luaran PkM}

Publikasi PkM pada Media Warta Kota.
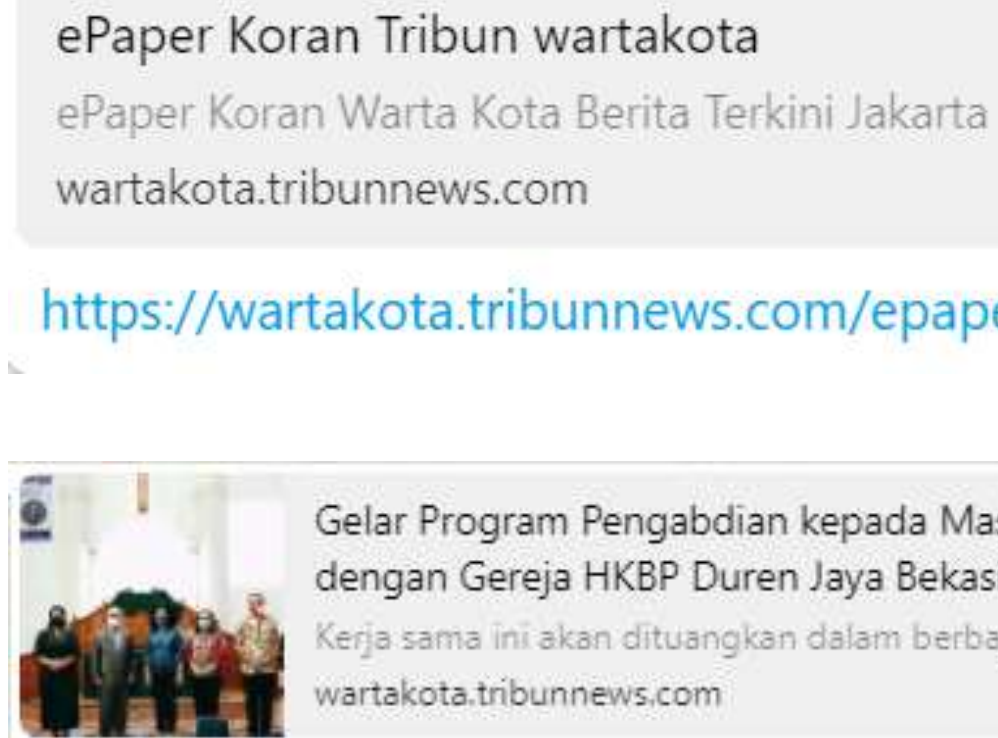

Gelar Program Pengabdian kepada Masyarakat UKI Kerja Sama dengan Gereja HKBP Duren Jaya Bekasi - Warta Kota

Kerja sama ini akan dituangkan dalam berbagai bentuk kegiatan dalam wartakota.tribunnews,com

https://wartakota.tribunnews.com/2020/07/19/gelar-program-pengabdiankepada-masyarakat-uki-kerja-sama-dengan-gereja-hkbp-duren-jaya-bekasi

Selain publikasi pada sosial media akan dipublikasi pada jurnal Comunita Servizio LPPM UKI

e. Analisis Data

Analisis data dengan dekriptif yakni mendeskripsikan demografi peserta seminar dan mendeskripsikan kebermanfaatan seminar (Cresswell, J., 2018). 
Volume 2, Nomor 2, Tahun 2020 Hal 393 - 405

\section{HASIL DAN PEMBAHASAN}

1. Karakteristik responden

1. Berdasarkan gender.

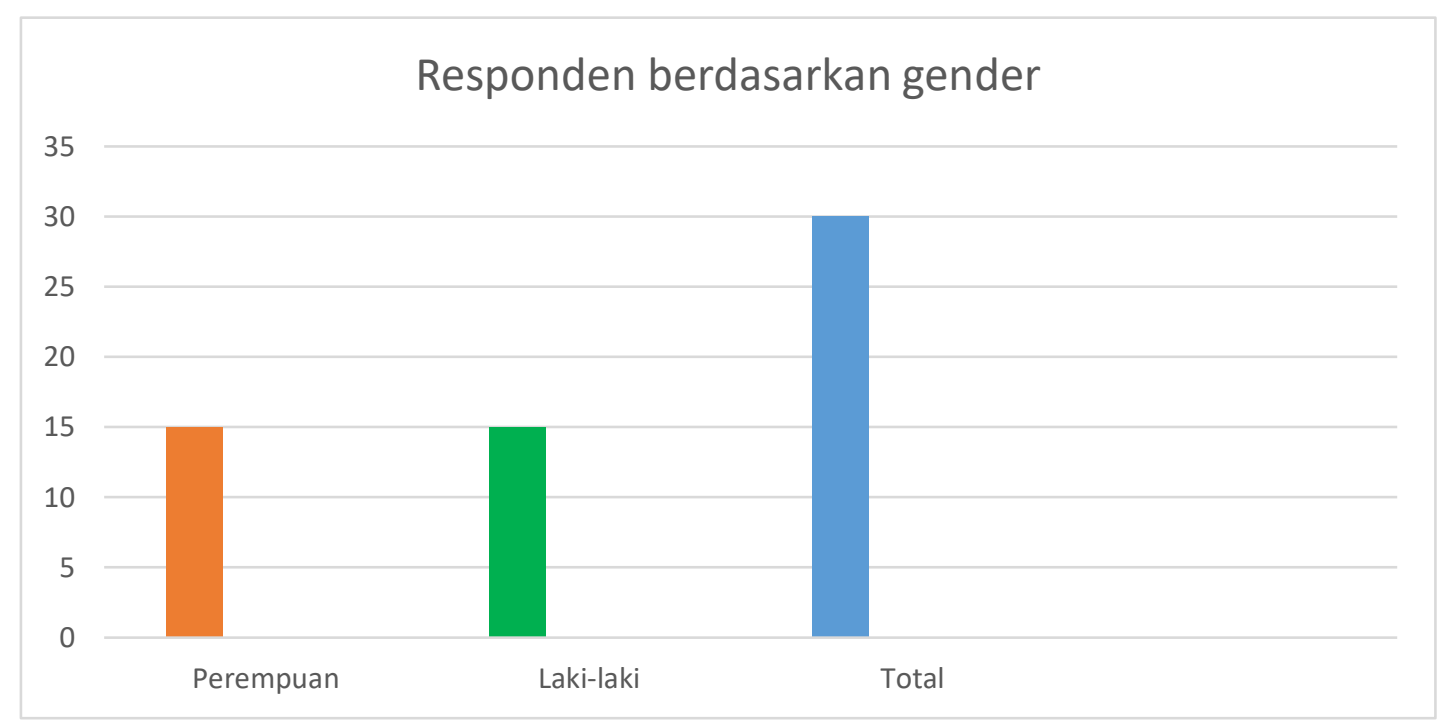

Gambar 4.1 Responden berdasarkan Gender

2. Berdasarkan gambar 4.1 menunjukkan terdapat 15 orang perempuan dan 15 orang laki-laki.

3. Berdasarkan usia

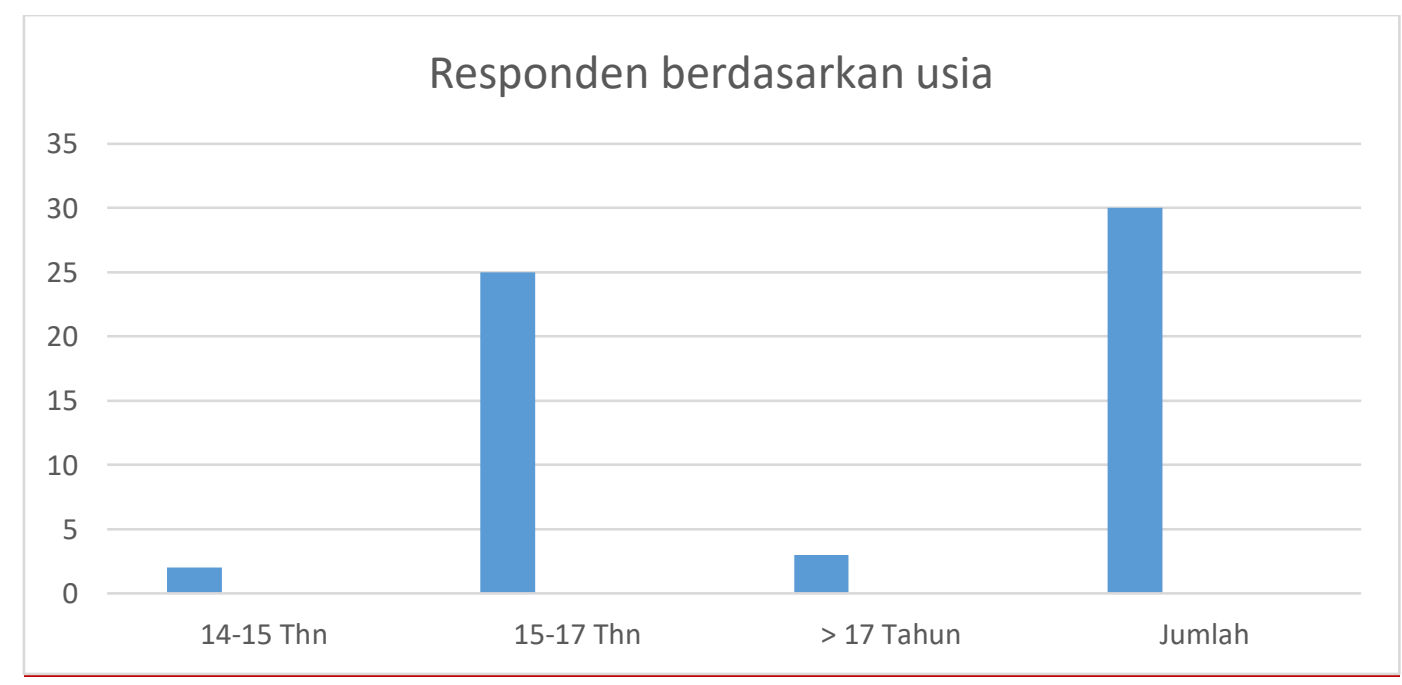

Gambar 4.2 Responden berdasarkan umur

Berdasarkan gambar $\quad 4.2$ menunjukkan terdapat 2 orang responden berumur 14-15 tahun, 25 orang berusia 15- 
17 tahun, dan 1 orang berusia lebih dari 17 tahun. Dapat dimaknai dari aspek umur masih dalam kategori remaja yang akan beranjak dewasa. Dalam usia remaja perlu pendampingan orangtua untuk memotivasi belajar, dan mengarahkan pergaulan positif dengan membentuk kelompok belajar. Remaja perlu diberikan pengetahuan tentang narkoba, dampak narkoba, sanksi jika terlibat narkoba. Pengetahuan itu diberikan agar dari dini tidak ikut pergaulan bebas

\section{Berdasarkan Tingkat Sekolah}

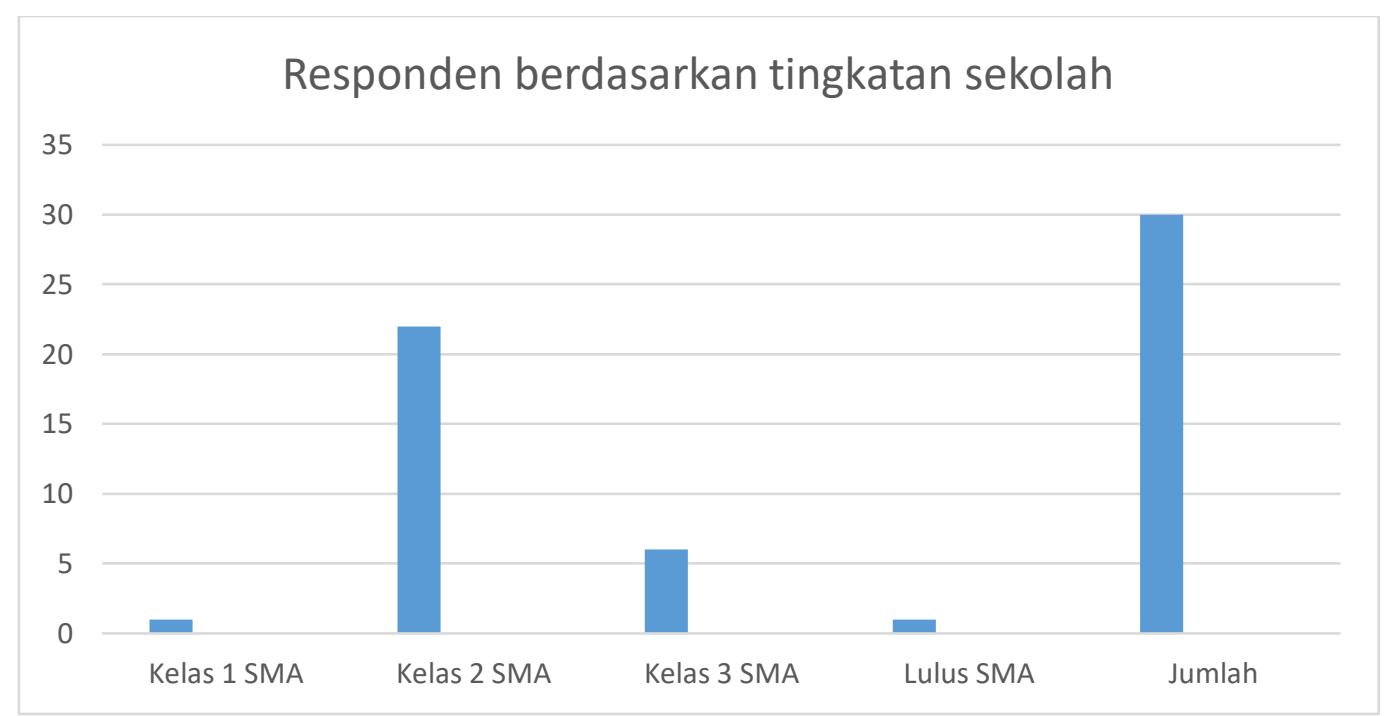

Gambar 4.3 Responden berdasarkan tingkatan sekolah

Berdasarkan gambar 4.3 responden kelas 1 SMA sebanyak 1 orang, kelas 2 SMA sebanyak 22 orang, kelas 3 SMA sebanyak 6 orang, dan lulus SMA sebanyak 1 orang. Informasi ini penting bagi UKI selain memberikan penguatan bagi para remaja turut sekaligus memberikan pencerahan untuk memilih perguruan tinggi yang tepat. UKI merupakan pilihanyang tepat karena tetap tinggal bersama orangtua, lokasi UKI strategis, dan UKI memiliki keunggulan tempat menuntut ilmu dan sekaligus mendidik nilai-nilai kristen agar terbentuk karakter yang kuat.
2. Kebermanfaatan PkM

Narasumber-1 memaparkan materi Generasi Sehat Di Masa Pandemic Covid 19 Dan Tetap Berprestasi Di New Normal Di Tinjau Dari Aspek Hukum. Narasumber -2 memaparkan Strategi Belajar Mandiri di Masa Pandemi Covid19. Narasumber-3 memaparkan Narkotika dan pencegahan narkotika. Ketiga narasumber memaparkan materi dengan sangat baik. Peserta sangat serius menyimak. Setelah selesai pemaparan dilanjutkan dengan sesi tanya jawab.

Peserta yakni pelajar sidi merasakan adanya hambatan belajar di rumah selama pembelajaran jarak jauh diantaranya 
komunikasi siswa dengan guru terbatas. Kadang-kadang guru tidak merespon pertanyaan siswa. Siswa diberikan tugas tanpa ada penjelasan materi terlebih dahulu. Siswa merasa kurang mendapatkan pengetahuan jika dibandingkan dengan belajar di sekolah. Selain itu dirasakan yang menjadi penghambat adalah jaringan internet tidak stabil.

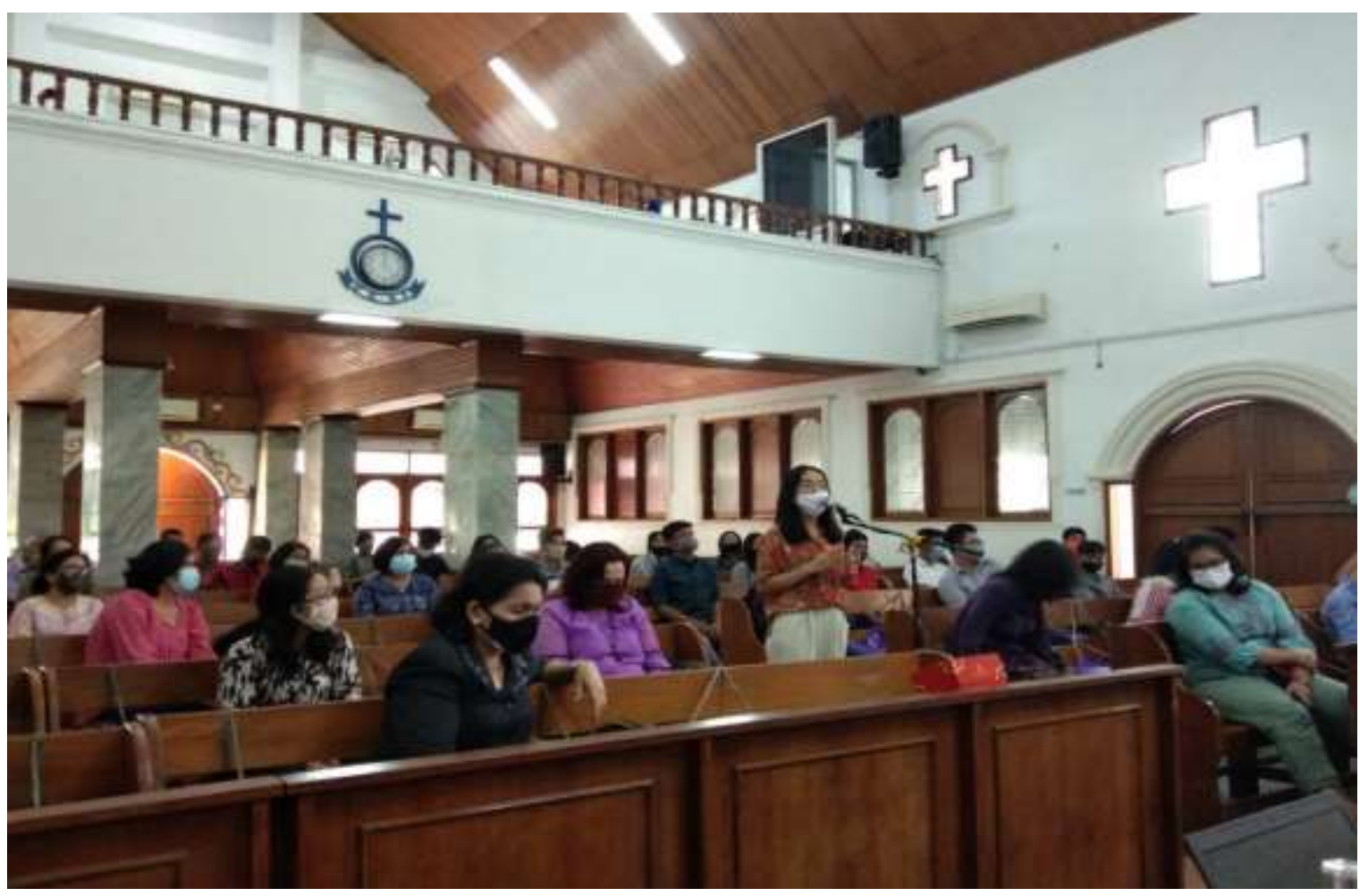

Gambar 4.4 Peserta sidi bertanya

Responden pelajar sidi menanyakan strategi belajar mandiri yang efektif karena selama pandemi Covid 19 mengakibatkan PJJ dan saya mengalami kesulitan belajar? Narasumber memberikan penjelajasan bahwa strategi efektif yakni siswa dilatih (1) Mengelola WAKTU; (2) Membaca cepat; dan (3) Merekam hasil baca (dengan membuat resume, outline, dan peta konsep)

Orangtua pelajar sidi dan majelis gereja menayakan apakah LGBT merupakan faktor turunan dan bagaimana peran orangtua dalam mengawasi anak? Narasumber menjelaskan bahwa LGBT bukan merupakan genetik. Oleh karena itu orangtua mengawasi anak di rumah maupun di luar rumah. Berikan tust kepada anak bahwa anak melakukan kegiatan sesuai dengan arahan orangtua. Orangtua mengawasi anak melalui jadwal belajar yang di serahkan kepada orangtua. 


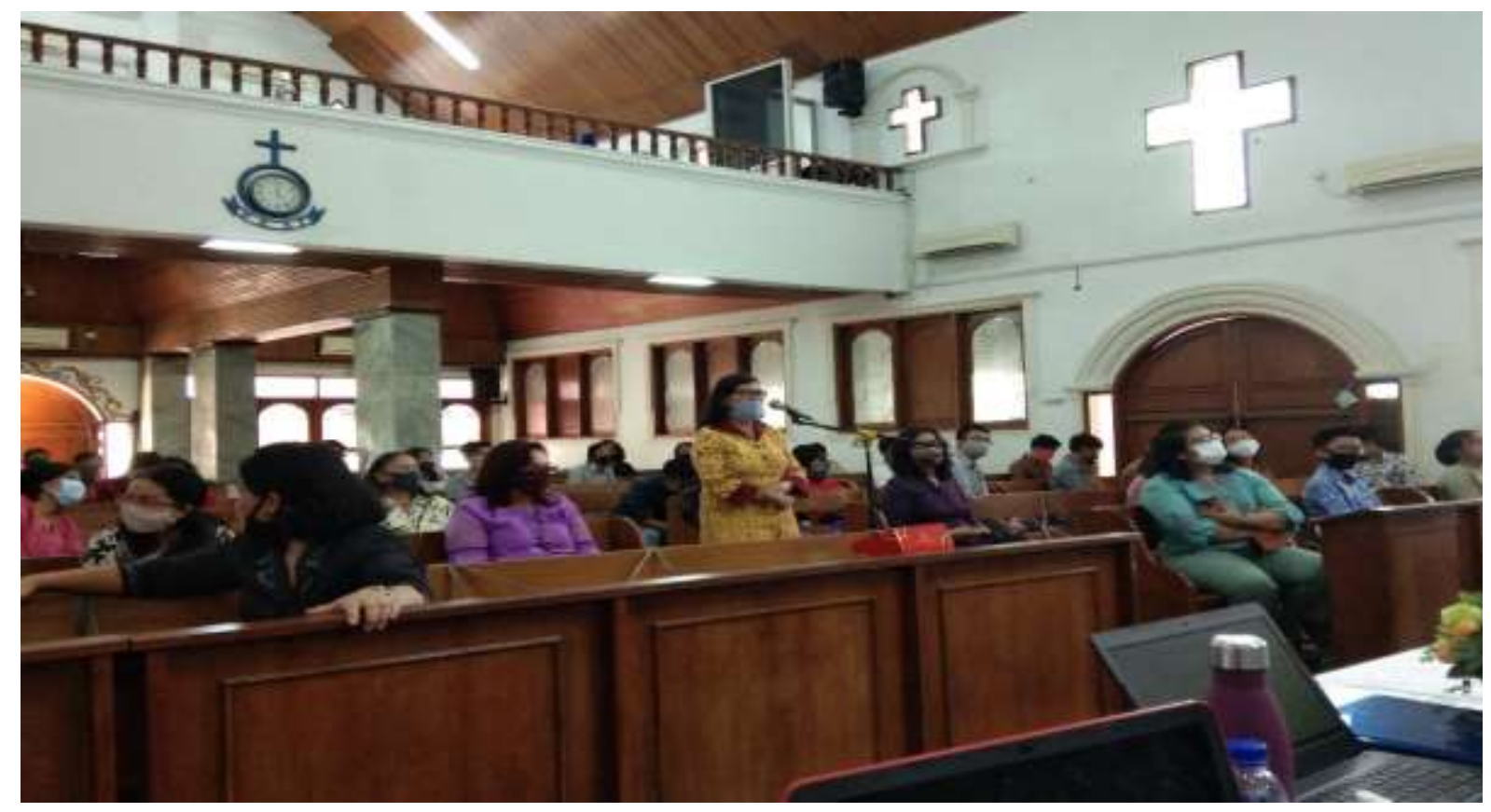

Gambar 4.5 Orangtua bertanya Narasumber menjawab pertanyaan orantua bahwa LGBT bukanlah

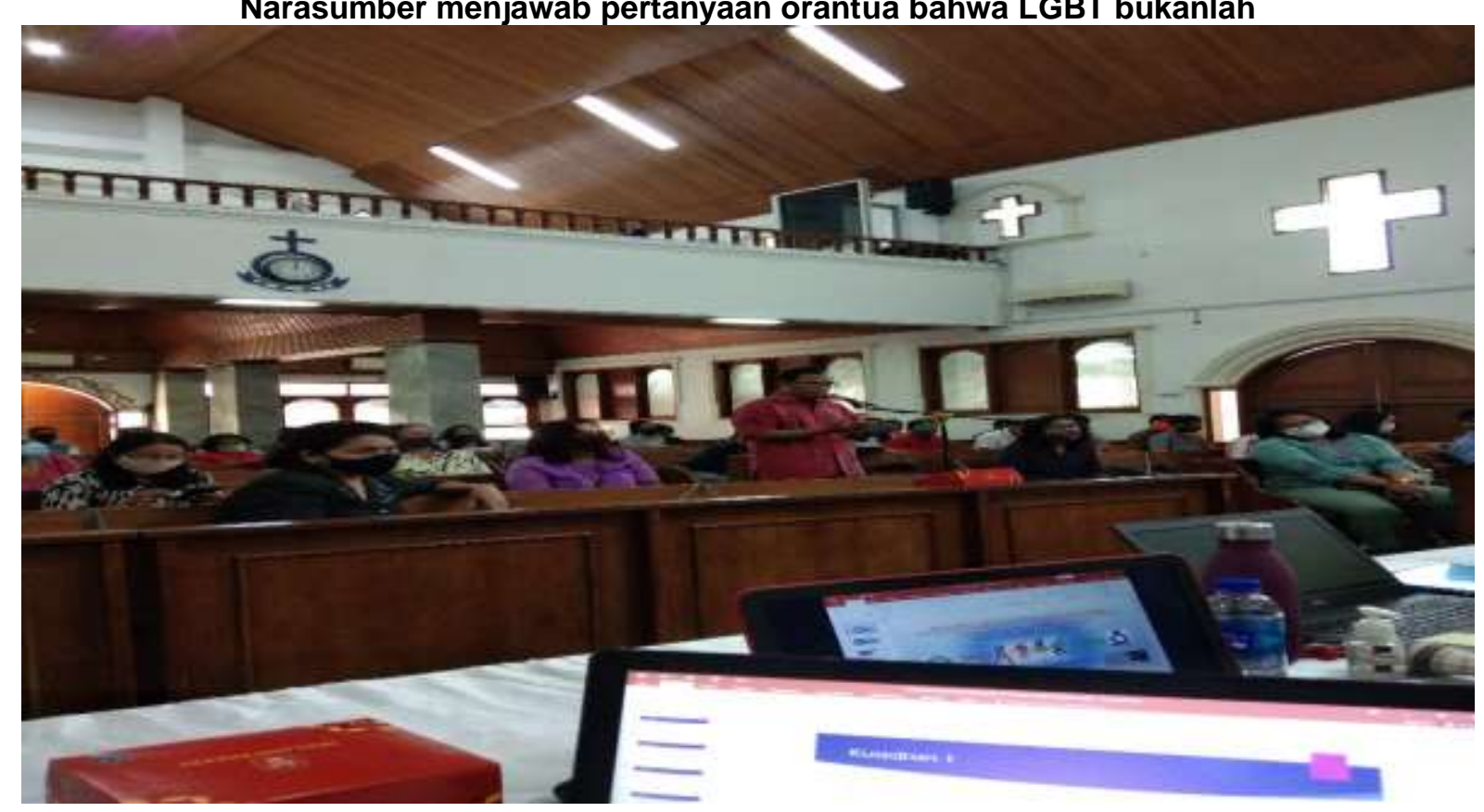

Gambar 4.6 Majelis gereja bertanya

\section{SIMPULAN}

Kegiatan pengabdian kepada masyarakat Prodi Administrasi Pendidikan Program Program Pascasarjana UKI disambut baik oleh Pimpinan gereja, majelis, orangtua jemaat. Kehadiran UKI di gereja HKBP Duren Jaya sangat bermanfaat menguatkan dan menambah wawasan pelajar sidi sehingga menjadi generasi penerus yang berkarakter kristiani yang tangguh. 


\section{UCAPAN TERIMA KASIH}

Pertama-tama peneliti mengucapkan rasa syukur kepada Tuhan Yang Mahakuasa karena peneliti dapat menyelesaikan penulisan laporan penelitian yang berjudul: Kepuasan Hidup Dan Inisiatif Pengembangan Diri Para Guru Honorer Di Sekolah Dasar SeJabodetabek. Penelitian ini didanai Univesitas Kristen Indonesia. Ucapan terima kasih kami sampaikan kepada Dr. Aartje Tehupeiory, SH, MH sebagai Kepala Lembaga Penelitian dan Pengabdian Masyarakat, Dr. Bintang R. Simbolon, M.Si. sebagai Direktur Program Pascasarsarjan, Dr. A. Dan Kia, M. Th. sebagai Wakil Direktur, Dr. Dra. Mesta Limbong, M.Psi sebagai Kaprodi Magister Administrasi Pendidikan. Terima kasih kami sampaikan kepada Pdt. Pantas Manalu, S.Th, sebagai pendeta resort dan Pdt. Rittar Simorangkir, S.Th sebagai pendeta fungsionaris, majelis gereja HKBP Duren Jaya yang telah berkenan bermitra dengan UKI. Akhirnya kepada semua pihak yang telah membantu baik dalam persiapan proposal PkM maupun pelaksanaan PkM kami sampaikan terima kasih. Semoga Tuhan yang Maha Pengasih membalas baik budi bapak/saudara/i sekalian.

\section{REFERENSI}

Anfas, A. (2020). Pengaruh Pelatihan Keterampilan Belajar Mandiri Terhadap Motivasi Belajar Mahasiswa Pada Pendidikan Jarak Jauh. Jurnal Pendidikan, 21(1), 1827.

Cresswell, J. (2018). Chapter 1: The selection of a research approach in Cresswell J. Research design: Qualitative, Quantitative, And Mixed Methods Approaches.

Darmayanti, T. (2008). Efektivitas intervensi keterampilan self- regulated learning dan keteladanan dalam meningkatkan kemampuan belajar mandiri dan prestasi belajar mahasiswa pendidikan jarak jauh. Jurnal pendidikan terbuka dan jarak jauh, 9(2), 68-82.

Sihotang, H. (2010). Hubungan Antara Kemampuan Berpikir Kritis dan Gaya Belajar Dengan Hasil Belajar Matematika Siswa Kelas VIII SMP Negeri 255 Jakarta. Jurnal Dinamika Pendidikan, 3(3), 160-169.

Nadeak, B., Sormin, E., Naibaho, L., \& Deliviana, E. (2020). Sexuality in Education Begins in The Home (Pendidikan Seksual Berawal Dalam Keluarga). Jurnal Comunita Servizio, 2(1), 254-264.

Suardana, I. K. (2012). Implementasi Model Belajar Mandiri untuk Meningkatkan Aktivitas, Hasil, dan Kemandirian Belajar Mahasiswa. Jurnal Pendidikan dan Pengajaran, 45(1).

Sihotang, H., Limbong, M., Simbolon, B. R., Tampubolon, H., \& Silalahi, M. (2019). Peningkatan Kompetensi Guru Dalam Mengimlementasikan Kurikulum 2013 Dalam Education 4.0. JURNAL ComunitÃ Servizio: Jurnal Terkait Kegiatan Pengabdian kepada Masyarakat, terkhusus bidang Teknologi, Kewirausahaan dan Sosial Kemasyarakatan, 1(2), 223-234.

Guswantoro, T., Lumbantobing, S. S., \& Malau, N. D. (2019). PELATIHAN MEDIA PEMBELAJARAN KEPADA GURU-GURU YAYASAN PENDIDIKAN MUHAMMAD SYATIR AL-GHAZALI TANGERANG SELATAN. JURNAL ComunitÃ Servizio: Jurnal Terkait Kegiatan Pengabdian kepada Masyarakat, terkhusus bidang Teknologi, Kewirausahaan dan Sosial Kemasyarakatan, 1(1), 28-36. 